\title{
Plasticity in Root Length and Volume Through the Alternate Wetting and Drying Water Management in Rice
}

\author{
Giovani Greigh de Brito ${ }^{1}$, Paulo Ricardo Reis Fagundes ${ }^{1}$, André Andres ${ }^{1}$, Jaqueline Trombetta da Silva ${ }^{3}$, \\ Juliano de Bastos Pazini ${ }^{2} \&$ José Maria Barbat Parfit ${ }^{1}$ \\ ${ }^{1}$ Empresa Brasileira de Pesquisa Agropecuária, Pelotas, RS, Brazil \\ ${ }^{2}$ Doutorando em Fitossanidade, Departamento de Fitossanidade, Universidade Federal de Pelotas, Pelotas, RS, \\ Brazil \\ ${ }^{3}$ Instituto Federal de Educação, Ciência e Tecnologia do Rio Grande do Sul, Campus Sertão, Sertão, RS, Brazil \\ Correspondence: Giovani Greigh de Brito, Department of Research and Development, Brazilian Agricultural \\ Research Corporation-Embrapa Temperate Agriculture (Embrapa Clima Temperado), Rodovia BR 392, km 78, \\ CEP: 96010-971, Pelotas, RS, Brazil. Tel: 55-533-275-8480. E-mail: giovani.brito@embrapa.br
}

Received: December 3, 2018 Accepted: January 21, $2019 \quad$ Online Published: March 15, 2019

doi:10.5539/jas.v11n4p294 URL: https://doi.org/10.5539/jas.v11n4p294

The research is financed by Brazilian Agricultural Research Corporation (EMBRAPA).

\begin{abstract}
Saving water via rational management in paddy rice require efforts to minimize risks to food security, whether consider that its adoption by farmers generally lead to lower grain productivity. Recently, studies by meta-analysis approaches highlight that when soil water potential was higher than $-20 \mathrm{kPa}$, grain yields are not significantly decreased. In this context, new efforts should be done by rice breeders aiming to improve the plant performance when submitted to a more severe alternate wetting and drying (AWD) aiming to face the increasingly extreme climatic events in the next decades. Thus, in this first-tier of the study, our main objective was to evaluate the responses of a genotypes set (cultivars and elite line) for some root traits plasticity and its potential to change gas exchange attributes and grain yield when plants are subjected to severe AWD irrigation management, even when soil water potential beyond this threshold (when soils dried beyond $-20 \mathrm{kPa}$, even reaching $-40 \mathrm{kPa}$ ). Our data highlight that the mean grain yield across genotypes ranged from 9.25 to 12.65 ton/ha when maintained under continuous flooding (CF) and from 9.52 to 11.67 ton/ha at AWD water management. Root plasticity responses across evaluated genotypes under AWD management were highlighted; BRS Pampa cultivar and Titan CL hybrid showed the greater plasticity index for total root length and total root volume. Data suggests that under severe AWD management, root plasticity in terms of more total root length and total root volume at $0-20 \mathrm{~cm}$ depth can leads to some contribution degree for higher grain yield and for its stability under AWD practice. These results can serves as a starting point to additional efforts via physiological breeding approaches aiming the construction of rice plant ideotypes more suitable for AWD management, especially take into account its contributions to mitigate potential impacts of future climate changes on food security.
\end{abstract}

Keywords: Oryza, AWD, water use efficiency, drought, intermittent irrigation, physiological breeding

\section{Introduction}

The increasingly occurrence of extremes climate events and those forecast to occur yet in the century wave us that our current decisions will determine the size of the climatic impacts on earth life in the next years. Although is unclear the size impacts of these changes on agricultural sustainability, in the current year the $\mathrm{CO}_{2}$ concentration reached unprecedented registered levels on earth surface (about $403 \mathrm{ppm}$ ) (Olivier et al., 2017). Recently, progress show enhances drying of the Southern Hemisphere and reduces drying of the Northern Hemisphere, increases the formation of Antarctic sea ice (consistent with recent observations of increasing Antarctic sea-ice area) and warms the subsurface ocean around the Antarctic coast (Bronselaer et al., 2018). These climate scenarios will can negatively impact on agricultural sustainability in the present and in the future. 
In this way, add to challenges associated to feed more than nine billions people in the next decades (Fan \& Brzeska, 2014; Jacquemin et al., 2013), an additional question is related to how supply the food crescent demand by world growth population in face of increasingly uncertainties about climate stability; which could lead to change of rain regime, besides of increases in frequency of heat and cold waves as predicted to be increasingly common in next decades. In this sense, abiotic and biotic stresses will be the major constraints for agricultural productivity on the global scale and projected climate changes could increase their negative effects in the future (Brito et al., 2010, 2011, 2016; Diola et al., 2011, 2013; Guimarães et al., 2017; Weber et al., 2014). Beyond of the predict impact of these extreme climatic events on global population remain unclear, its occurrence will probably influence the plant species distributions, productivity, carbon balance and negatively impacting on physiological resilience capacity of plants in a specific environment. Thus, is imperative to consider that the major challenge is how to overcome this barriers increasing rice production with less land, water, chemicals, and labor; considering still the need to conserve the environmental and natural resources of degradation. In this way, efforts and new strategies are necessary in the rice breeding programs aiming define innovative procedures/tools and means to accelerate the construction of new plant types for new economics and climate scenarios (Moura et al., 2017, 2018a, 2018b; York et al., 2013).

In the Brazilian southern producer region, about 1.2 million hectares of paddy rice (CONAB, 2018) are annually cropped predominantly under continuous flooded irrigation. Under this irrigation system, approximately 6,435 $\mathrm{m}^{-3}$ of water per hectare per cycle are used (Parfitt et al., 2018), disregarding water available via rainfall precipitation, that in this region reach historically $450 \mathrm{~mm}$ per growth season (Fageria et al., 2014). In this context, the alternate wetting and drying (AWD) system of irrigation could be used aiming increase the water use efficiency and at same time, reduce energetic costs involved in water capture and its distribution, as traditionally made by most of the farmers that yet adopt the continuous flooded system in paddy rice. In addition, refinements in the AWD could lead to an alternative by farmers to face the negative impacts of climate change on rain distribution regime in the future, besides leads them to decreases in its production costs. When AWD is adopted, water management is carried out via intermittent flooding, which alternate cycles of saturated and unsaturated soil conditions. Under this practice, during specific development phase, the water entry is closed allowing them to subside until the soil reaches a threshold of water potential, after which the field is reflooded. Different studies has highlighted the negative impacts of continuously flooded rice system can be addressed with the implementation of AWD, in many cases yields are reduced (Carrijo et al., 2017). Meta-analysis carry out by these authors showed that the degree of soil drying during the drying events was critical to ensuring that yields were maintained. Additionally, they reported that with mild AWD (soil water potential at root depth bigger than $-20 \mathrm{kPa}$ or perched water did not drop below $15 \mathrm{~cm}$ from the soil surface) not significantly reduce the grain yield, but were reduced on average by $23 \%$ with severe AWD (soil water potential at root depth smaller than $-20 \mathrm{kPa}$ ).

The phenomenon of phenotypic plasticity can be defined as the ability of a genotype to change its phenotype in response to changing environmental conditions (O'Toole \& Bland, 1987). In this context, phenotypic plasticity can lead to mitigate the effect of stress; thus, maintain stability of grain yield and/or its quality. In this sense, the rice phenotypic plasticity can involve its chlorophyll content, osmotic adjustment, photosynthesis, transpiration and respiration performance, as well as plant architecture adjustments such as tillers emissions rate, leaf size, leaf thickness, leaf angle and, so many other parameters. Relative to root plasticity capacity, the difficulty to accessing them and the laborious procedures involved has been limited the progress in the understanding the role size of root architecture and its plasticity response as a contributor for plant performance under hard environments. On the other hand, in last decades, advances achieved in the development of devices and software has allowed to glimpse new progresses aiming dissect the role of plasticity phenomenon on plant productivity; these progress could be crucial in the plant ideotype definition by breeders aiming to design plant to face the future climate scenarios. These technological advances has allowed progress in the understanding of the role of the soil moisture fluctuation on the plasticity in aerenchyma development and lateral root production, which can contribute to maintenance of root system development under transient drought-to-waterlogged stress condition and vice versa, respectively (Niones et al., 2012; Suralta et al., 2010). Additionally, the plasticity in root system development based on total root length at the shallow soil layer has been emphasized as important contributor in the capture of the available water after the onset of rainfall. However, the ability for deep root system development can allow the access of a greater volume of water from the deeper soil layer during periods of water deficit periods (Henry et al., 2011; Uga et al., 2013). In rice rainfed lowland or under those managed under alternate wet and drying irrigation these two variables have been suggested to improve adaptation to this water fluctuations during development cycle of the plants. 
Under this water management practice, there are gaps especially in knowledge about the size of root plasticity contribution on photosynthesis performance and rice grain productivity when AWD is adopted. Although, there were recorded advantages of the adoption of AWD leading a reduction of water inputs when compared to continuous flooded and its positive effects on decreases in the levels of toxic element such as arsenic, besides reduce methane emissions from paddies (Yang et al., 2017), so far, few studies has been conducted, at field conditions, to evaluate the responses of elite lines and cultivars for some root traits plasticity and its potential contribution to gas exchange attributes and grain yield when plants are subjected to severe AWD imposing, when soil water potential beyond this threshold (when soils dried beyond $-20 \mathrm{kPa}$, even reaching $-40 \mathrm{kPa}$ ). Thus, the knowledge of the potential contribution of root plasticity on some gas exchange attributes and on grain yield performance or stability when AWD is adopted is the starting point in the definition of new plant ideotype to face present and future climate scenarios. This study aiming knowledge advances in water management practice, which should be associated to breeding efforts aiming to quantify the morphophysiological traits, which can contribute to high grain yield or result in grain stability when a more severe AWD management has to be adopted in the near future. Thus, this knowledge will allow the breeding to do modification in root systems architecture presently in cultivars adapted to continuous flooded, which could allow designing new roots ideotype aiming to optimize the AWD, leading consequently in higher grain yield or grain stability in future climate scenarios.

Is imperative consider that along of decade all rice breeding efforts made for Brazilian southern producer region were concentrated in the development of cultivars adapted to continuous flooded irrigation system, where resources as such nutrients and water are concentrated in a relatively shallow zone. However, in the context of AWD irrigation practice, new efforts will be need aiming obtain knowledge about how root traits can contribute to optimize the resources use, what type of root architecture is more suitable for this water management purpose and what the size of contribution of root plasticity for grain yield and its stability when AWD is adopted. In this context, Embrapa's rice breeding program has been initiated studies aiming to evaluate the contribution of some root traits plasticity on some gas exchange performance and its role in rice grain yield stability in paddy rice when plants are subjected to severe AWD management practice. For this purpose, in this first-tier, our main objective was to evaluate the responses of elite lines and cultivars for some root traits plasticity and its potential changes in gas exchange attributes and in grain yield when plants are submitted to severe AWD imposing, in soil water potential beyond this threshold (when soils dried beyond $-20 \mathrm{kPa}$, even reaching $-40 \mathrm{kPa}$ ).

\section{Material and Methods}

\subsection{Plant Materials and Environment Conditions}

The plant materials were comprised of traditional varieties (BRS Pampa, BRS 358, IRGA 430, Guri-INTA CL and Lemont), an elite breeding line (AB14738) from breeding program of Brazilian Agricultural Research Corporation (Embrapa) and a hybrid (Titan CL) from a private company, which belonging to the early maturation group. These genotypes have similar life cycles and show similarity in grain yield potential; except for Lemont cultivar and AB14739 line, the agronomics characteristics, grain quality and its diseases resistance performance are recorded at technical recommendations for South-Brazilian region (SOSBAI, 2016).

In the cropping season 2017/2018, the experiment was carry out under field conditions, at Low-Land Embrapa Experimental Station (LLEES), located near Pelotas city, Rio Grande do Sul state, Brazil. Soil is classified as a

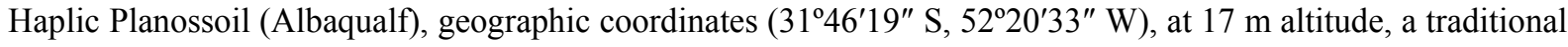
region for rice production under flooding irrigated system. Before planting, this area was left fallow for two years (as well as commonly adopted by farmers). The conventional soil tillage operations, based on plowing followed by two harrowing, were adopted. Crop management throughout the growing season was carried out according to the Brazilian Official recommendation for rice (SOSBAI 2016), including fertilizer management. Thus, Starter fertilizer was $15 \mathrm{~kg}$ of N ha ${ }^{-1}, 60 \mathrm{~kg}$ of P2O5 ha ${ }^{-1}, 60 \mathrm{~kg}$ of K2O ha ${ }^{-1}$ bank-applied adjacent to each row at sowing date. The additional nitrogen was $50 \mathrm{~kg}^{-1} \mathrm{~N} \mathrm{ha}^{-1}$ applied at $\mathrm{V}_{4}$ growth stage (tillering initiation) and $60 \mathrm{~kg}$ of $\mathrm{N} \mathrm{ha}^{-1}$ at $\mathrm{R}_{1}$ growth stage (panicle differentiation) (Counce et al., 2000); soil chemical parameters are shown in Table 1. 
Table 1. Soil chemical characteristics from $0-20 \mathrm{~cm}$ of the soil profile in lowland Experimental Station (LLES), Embrapa Temperate Climate, Pelotas, RS, Brazil

\begin{tabular}{|c|c|c|c|c|c|c|c|c|c|}
\hline LLES & M.O. & $\mathrm{pH}$ & $\mathrm{P}^{*}$ & $\mathrm{~K}^{+}$ & $\mathrm{Ca}^{2+}$ & $\mathrm{Mg}^{2+}$ & $\mathrm{Al}^{3+}$ & CTC & V \\
\hline Samples† & $\%$ & water & --- & $\mathrm{lm}^{3}$------ & ---- & ------ & $\mathrm{dm}^{3}$ & ------------ & $\%$ \\
\hline 36449 & 1.5 & 5.7 & 27.0 & 60.0 & 2.8 & 1.6 & 0.0 & 4.7 & 59.0 \\
\hline 36450 & 1.4 & 5.8 & 38.5 & 65.0 & 2.7 & 1.6 & 0.0 & 4.6 & 55.0 \\
\hline
\end{tabular}

Note. ${ }^{*} \mathrm{P}$ was extracted using Mellish solution and $\mathrm{pH}$ was measured in water. $\dagger$ Two samples replicates were analyzed.

\subsection{Agronomic Management and AWD System Implementation}

The effects of AWD irrigation practice on some root morphometric traits and its root plasticity contribution on photosynthesis performance and on rice grain yield were evaluated in field experiment conducted in the LLEES in 2017/2018 growth season. For this purpose, genotypes of same maturation group (early) were sowing on November $13^{\text {th }}, 2017$, considering the best window time for rice sowing in the Brazilian south region. The experiment was carry out in a randomized complete-block design with a split plot treatment structure. The water regimes were the whole plot, and combinations of genotypes were allocated to the sub-plots; four replications were used for all treatment combinations in each water regime. Importantly emphasize that the whole plot or principal plot was composed by water regimes (continuous flooded or alternate wetting and drying management) and genotypes were randomly allocated at into of this whole or principal plots. For each adopted water regime, principal plots were isolated by 6 meter from the other and arranged side by side. The sub-plots (genotypes) encompassed four rows spaced at $0.175 \mathrm{~m}$ from each other and measuring $5 \mathrm{~m}$ long, content 40 plants per meter density, approximately. Aiming to monitor the soil water tension, at $\mathrm{V}_{4}$ (when plant show four leaves with collars on the main stem (Counce et al., 2000) three sensors (Watermark ${ }^{\mathrm{TM}}$ electro-tensiometers, Irrometer Co, connected to a datalogger) were installed per plot at a depth of $10 \mathrm{~cm}$, in each replication, which in turn totalized twelve sensors for each water regime. This particular soil moisture sensor converts electrical resistance to a calibrated reading of centibars of soil water suction, ranging from 10-200 centibars.

For AWD water management, when plants reached $\mathrm{R}_{1}$ development phase (at panicle differentiation), the water entry was closed and drainage channels were opened allowing them to subside and until the soil reaches $-40 \mathrm{Kpa}$ threshold of water potential (average of 4-5 days to reach this soil water potential threshold); after which, the plots were reflooded being maintained under continuous flooding by $24 \mathrm{~h}$; after this time, the AWD cycles were repeated along of growth season $\left(\mathrm{V}_{4}-\mathrm{R}_{7}\right.$ development phases). Along with AWD treatment and, during the same time period a concurrent controlled treatment was undertaken in which approximately $7 \mathrm{~cm}$ of standing water was maintained, which in turn was named as continuous flooded (CF).

\subsection{Gas Exchange Measurements}

At $-40 \mathrm{kPa}$ of soil water potential in those plots subjected to AWD water management, the net assimilation rate $(P n)$ stomatal conductance $(g s)$ and transpiration rate $(E)$ were quantified between 09:00 and 11:00 $\mathrm{h}$ under artificial photosynthetic photon flux (PPF) $\left(1100 \mu \mathrm{mol} \mathrm{m}^{-2} \mathrm{~s}^{-1}\right)$ using a portable photosynthesis system infrared gas analyzer (Li-6400XT, Li-cor Biosciences, Lincoln, NE, USA). The interval time chosen for gas exchange measurement parameters considered the better time interval for a greater plant photosynthesis performance. The measurements were performed using a $\mathrm{CO}_{2}$ cartridge and a 6400-01 $\mathrm{CO}_{2}$ Injector System controlled the $\mathrm{CO}_{2}$ partial pressure entering the cuvette $(\mathrm{Ca}, \mu \mathrm{bar})$ maintaining them in $400 \mathrm{ppm}$. For all treatments, including those under continuous flooded, the measurements were carry out on flag leaves in six different plants $(n=6)$ per genotype. The mid to distal portion of each leaf blade was inserted in the leaf chamber for gas-exchange measurements. Gas exchange parameters were recorded after a stabilization period of about 2 minutes (total coefficient of variation $<0.5 \%$ ). The gas exchange measurements were carry out during three AWD cycles after the water management imposing.

\subsection{Root Samples and Root Phenotypic Plasticity}

Roots were sampled at the end of three AWD cycles under field conditions; four plants per genotype were sampled by digging a hole in the soil using whole plant core sampler; being sampled until $20 \mathrm{~cm}$ depth (Figure 1.). 

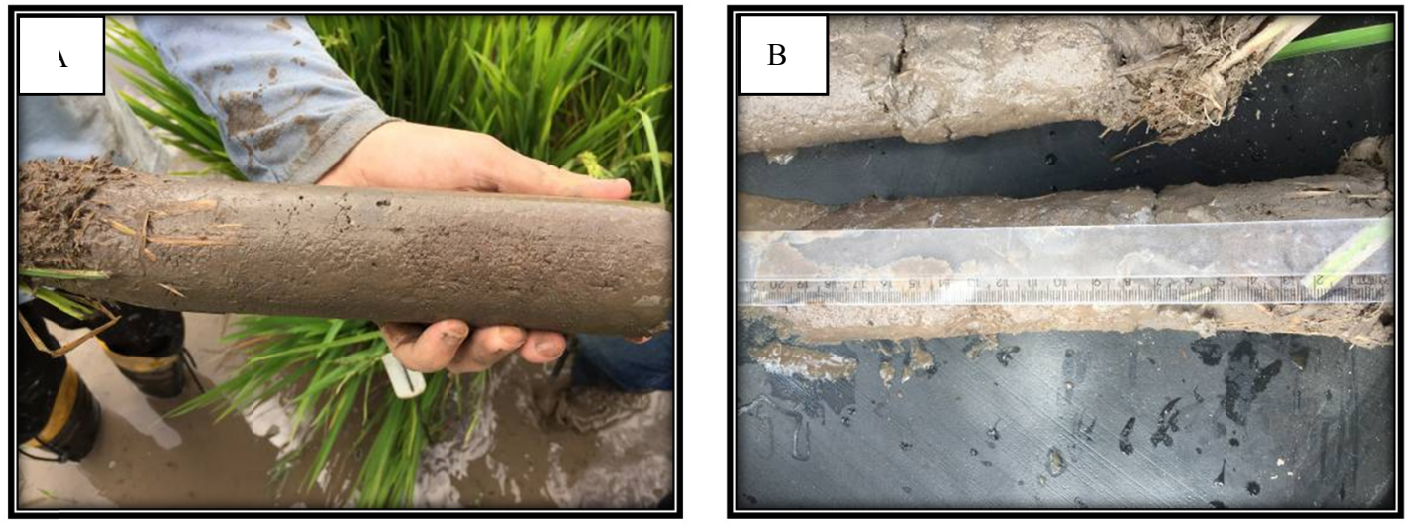

Figure 1. Ilighlighting the Root/soil samples in the procedures used under field conditions (A) and its samples dimensions (20 $\mathrm{cm}$ length and $50 \mathrm{~mm}$ diameter) (B)

Roots were immediately washed by tilting pots and carefully spraying with water until the attached soil and sand particles were removed. Subsequently, the roots were maintained overnight under a sodium hypochlorite solution $(5 \% \mathrm{v} / \mathrm{v})$. For wash procedures, a $0.5 \mathrm{~mm}$ diameter sieve was used to prevent loss of fine roots during washing. Samples were labeled, placed in plastic containers with lids, and stored in a $4{ }^{\circ} \mathrm{C}$ refrigerator. For analysis, roots were excised from main stem and tillers, placed in a plexiglas trays (200 by $300 \mathrm{~mm})$ with a 8-10 mm deep layer of water, and spread out with tweezers to minimize overlapping (Sandhu et al., 2016); after were imaged using a camera (Sony Ciber Shot DSC-HX1, Optical Zoom 20X), subsequently the images were analyzed with WinRHIZO PRO 2013a software (Regent Instruments. Inc., Quebec, Canada) (Moura et al., 2018). Average root diameter, total root volume and total root length were quantified and considered for subsequent statistical analysis.

For root plasticity index, root phenotypic plasticity was standardized as the response of root growth to an AWD treatment compared with the mean of all genotypes maintained under control conditions (flooded condition). As a field experiment, the root plasticity was calculating using data for average root diameter, total root volume and total root length at depths of 0 to $20 \mathrm{~cm}$.

For each root morphometric trait, plasticity was quantified using four plants in single replicates (subplot) from the AWD and its mean values from CF treatment:

$$
\text { Root plasticity }=\left[\mathrm{Y}_{\mathrm{AWD}}-\overline{\mathrm{Y}}_{\mathrm{CF}}\right] / \overline{\mathrm{Y}}_{\mathrm{CF}}
$$

This procedure allowed the standardization of the data and the use of all plants from a single replication for statistical analysis. $\mathrm{Y}_{\mathrm{AWD}}$ correspond to a specific root variable from a specific genotype, which was quantified under AWD; while $\overline{\mathrm{Y}}_{\mathrm{CF}}$ correspond to its mean values of all genotypes subjected to continuous flooding.

\subsection{Yield Components Measurements}

After the AWD period, all genotypes were reflooded being maintained under continuous flooding until a week before harvest. For each genotype, the border rows and $0.5 \mathrm{~m}$ rows extremities were excluded aiming minimize its interactions with plot central area. Thus, only $4 \mathrm{~m}$ of two central rows per plot were harvested; the grain weight was adjusted to $14 \%$ moisture content.

\subsection{Statistical Procedures}

A two-way statistical analysis of variance (ANOVA) was performed using SigmaPlot version 13). Normality and equal variance were done by Shapiro-Wilk and Brown-Forsythe, respectively; when necessary (normality equal variance tests failed), data were transformed by square roots procedures. For variables that failed for normality and/or equal variance, data transformation procedures were used. The data were expressed as the mean \pm standard error; means were statistically compared using student-Newman-Keuls's multiple-range test at the level of $p<$ 0.05. Additionally, a multivariate analysis via principal component analysis (PCA) was performed to identify relationship among genotypes and clarify the possibly occurrence of redundant evaluated parameters, besides of correlations among analyzed variables. For PCA, only those principal components with eigenvalues greater than on (1.0) were taken into consideration (Kaiser, 1958). This criterion results in the generation of more informative component of the original variables. Analyses were carried out using SigmaPlot version 13 (SigmaPlot 13.0-Systat Software San Jose). 


\section{Results}

Aiming to examine the potential effects of severe AWD (-40 kPa, soil water potential) on plasticity in total root length (TRL) and total root volume (TRV), its potential changes in gas exchange performance and on grain yield, evaluations were conducted under field conditions. Our data highlight that the mean grain yield across genotypes ranged from 9.25 to 12.65 ton/ha when maintained under continuous flooding (CF) and from 9.52 to 11.67 ton/ha at AWD water management (Figure 2A). BRS Pampa and Titan CL genotypes showed the highest grain yield performance under sever AWD management; These two genotypes also maintained higher photosynthesis, stomatal conductance and transpiration rate across imposed water regimes (Figures 2B, 2C and 2D).
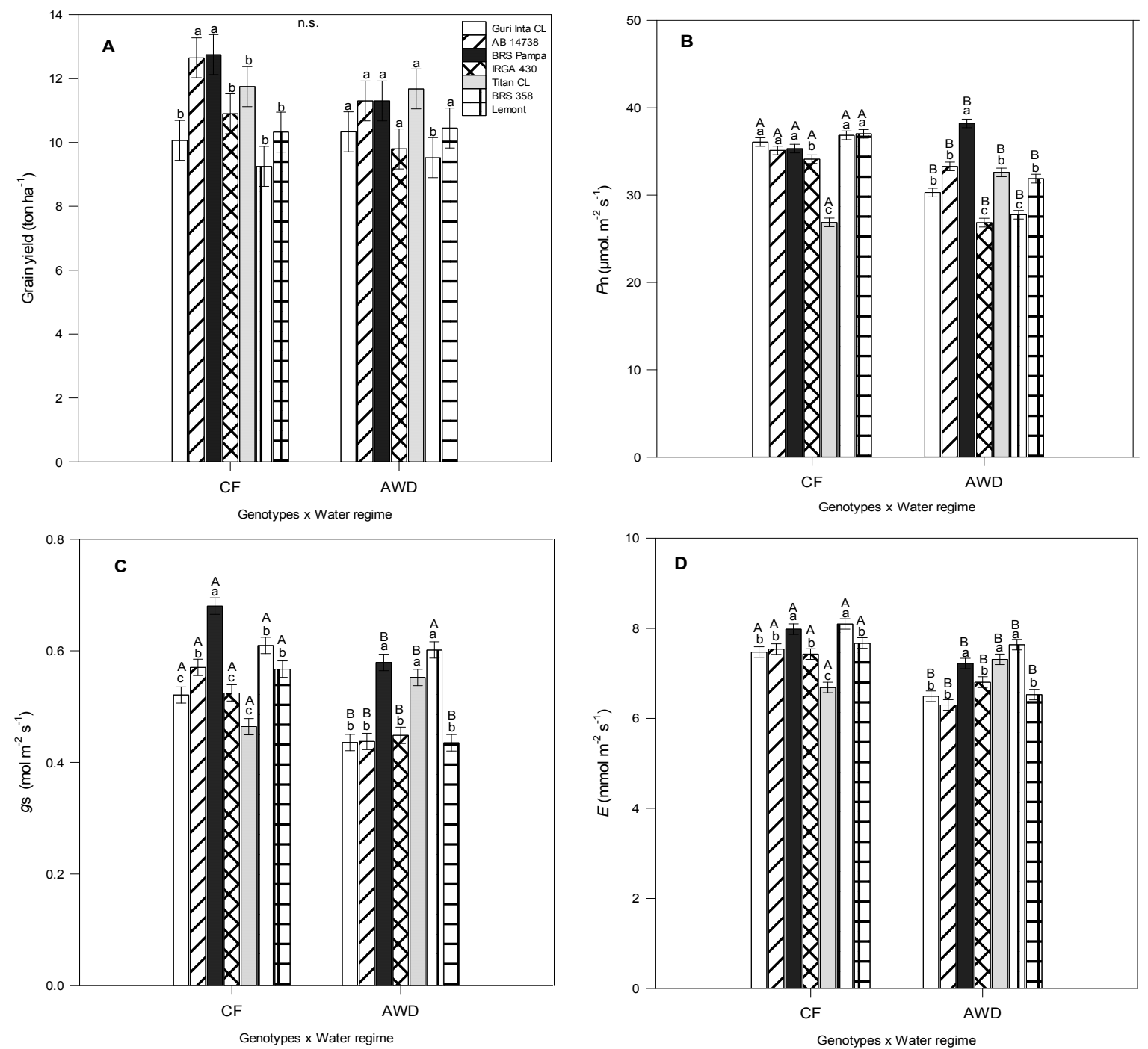

Figure 2. Severe AWD water management on grain yield (A), photosynthesis- $P \mathrm{n}(\mathrm{B})$, stomatal conductance- $g \mathrm{~s}$ $(C)$ and transpiration rate- $E(D)$. For gas exchange, the values are means $( \pm \mathrm{SE})$ of six plants, whereas, for grain yield the values refers to four replications (subplots)

Note. For all genotypes followed by the same lowercase letter on each water regime, they are not significantly different at the $\mathrm{p}<0.05$ level by the Student-Newman-Keuls test. For each genotype followed by the same capital letter, they are not significantly different at the $\mathrm{p}<0.05$ level by the Student-Newman-Keuls test between $\mathrm{CF}$ and $\mathrm{AWD}$ water management. n.s. means non-significant.

Interesting emphasize that in our study, the adopted severe AWD irrigation management led to the $40 \mathrm{kPa}$ of mean soil water potential, with some peaks (higher 60-80 kPa) during the short time of the day for a few sensors at the end of each stress cycle. Even when subjected to this soil tension level, the mean grain yield decreases 
were globally small (6\%). In general, compared to CF irrigation system, in the AWD irrigation management, there were decreases in photosynthesis $(8 \%)$, stomatal conductance $(12 \%)$ e transpiration rate $(9.6 \%)$ (Figure 2).

Root plasticity responses across evaluated genotypes under AWD management were highlighted; BRS Pampa cultivar and Titan CL hybrid showed the greater plasticity index for root length (TRL) and total root volume (TRV) (Figures 3A and 3B).
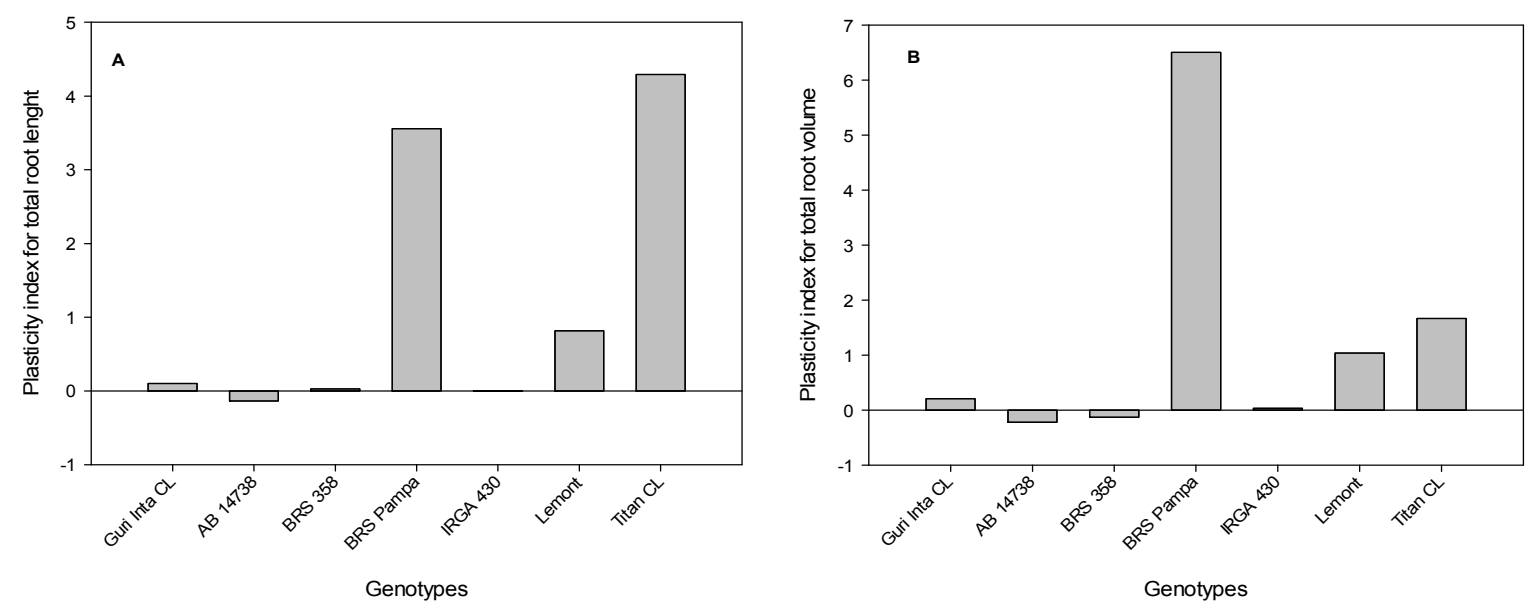

Figure 3. The plasticity in total root length (A) and total root volume (B) through the severe AWD management; measurements were carry out at the end of second severe AWD cycle. For two variables, the values are means $( \pm \mathrm{SE})$ of four plants of each genotypes sampled in a given water regime

Additionally, these two genotypes outperformed the set genotypes showing evident differential root plasticity for TRL and TRV, beside to maintain higher grain yield when subjected to severe AWD management.

Subsequently, a summary of the ANOVA of the parameters evaluated in this research is shown in Table 2; where are shown a significant interaction for the most of evaluated variables, besides genotypes and water regime effects. Water regime and water regime and genotypes interactions were not significant for AvgDiameter and Grain yield.

Table 2. Summary of the ANOVA from evaluated parameters in rice genotypes submitted to continuous flooding and severe alternate wetting and drying management

\begin{tabular}{lllll}
\hline Source of variation & & & \multicolumn{2}{c}{ Mean square } \\
\hline Gas exchange variables & DF & $P \mathrm{n}$ & $g \mathrm{~s}$ & $E$ \\
\hline Genotypes (G) & 6 & $47.10^{* *}$ & $0.029^{* *}$ & $1.045^{* *}$ \\
Water regime (W) & 1 & $119.66^{* *}$ & $0.057^{* *}$ & $6.033^{* *}$ \\
$\mathrm{G} \times \mathrm{W}$ & 6 & $60.00^{* *}$ & $0.012^{* *}$ & $0.79^{* *}$ \\
Error & 42 & 0.98 & 0.0008 & 0.05 \\
\hline Yield and root variables & $\mathrm{DF}$ & $\mathrm{TRL}$ & $\mathrm{TRV}$ & $\mathrm{GY}$ \\
\hline Genotypes (G) & 6 & $89.64^{* *}$ & $14.60^{* *}$ & $8.55^{* *}$ \\
Water regime (W) & 1 & $513.34^{* *}$ & $30.15^{* *}$ & $3.12^{\mathrm{ns}}$ \\
G x W & 6 & $134.57^{* *}$ & $11.08^{* *}$ & $1.25^{\mathrm{ns}}$ \\
Error & 42 & 3.38 & 0.59 & 1.56
\end{tabular}

Note. Abbreviated parameters as Pn: Photosynthesis $\left(\mu \mathrm{mol} \mathrm{m}^{-2} \mathrm{~s}^{-1}\right) ; g \mathrm{~s}$ : Stomatal conductance $\left(\mathrm{mol} \mathrm{m}^{-2} \mathrm{~s}^{-1}\right) ; E$ : Transpiration rate $\left(\mathrm{mmol} \mathrm{m}^{-2} \mathrm{~s}^{-1}\right)$; TRL: Total root length $(\mathrm{cm})$; TRV: Total root volume $\left(\mathrm{m}^{-3}\right)$. GY: Grain yield (ton $\mathrm{ha}^{-1}$ ). * significant at $\mathrm{p}<0.05, * *$ significant at $\mathrm{p}<0.01$ by the $\mathrm{F}$-test. ${ }^{\text {ns }}$ not significant at a threshold probability, by the F-test. For TRL and TRV which failed for equal of variance via Brown-Forsythe test, a subsequently square root transformation was used.

Multivariate statistical approaches via principal component analysis (PCA) identified two eigenvalues $>1$, which cumulatively explaining more than $80 \%$ of total variation for six traits considering the root plasticity index, gas 
exchange performance and grain yield values (Figure 4). The first PC explaining about 54\% of total variation also highlight its association with the genotypic variation for root trait plasticity, photosynthesis and grain yield (Figure A and B); whereas the second PC explain approximately 32\% of the total variation and was associated with stomatal conductance $(g \mathrm{~s})$ and transpiration rate. These two variables were more associated with root length plasticity when compared to the other root traits ones, suggesting some functional contribution of root length plasticity to maintain greater stomatal aperture when subjected to severe AWD water management.
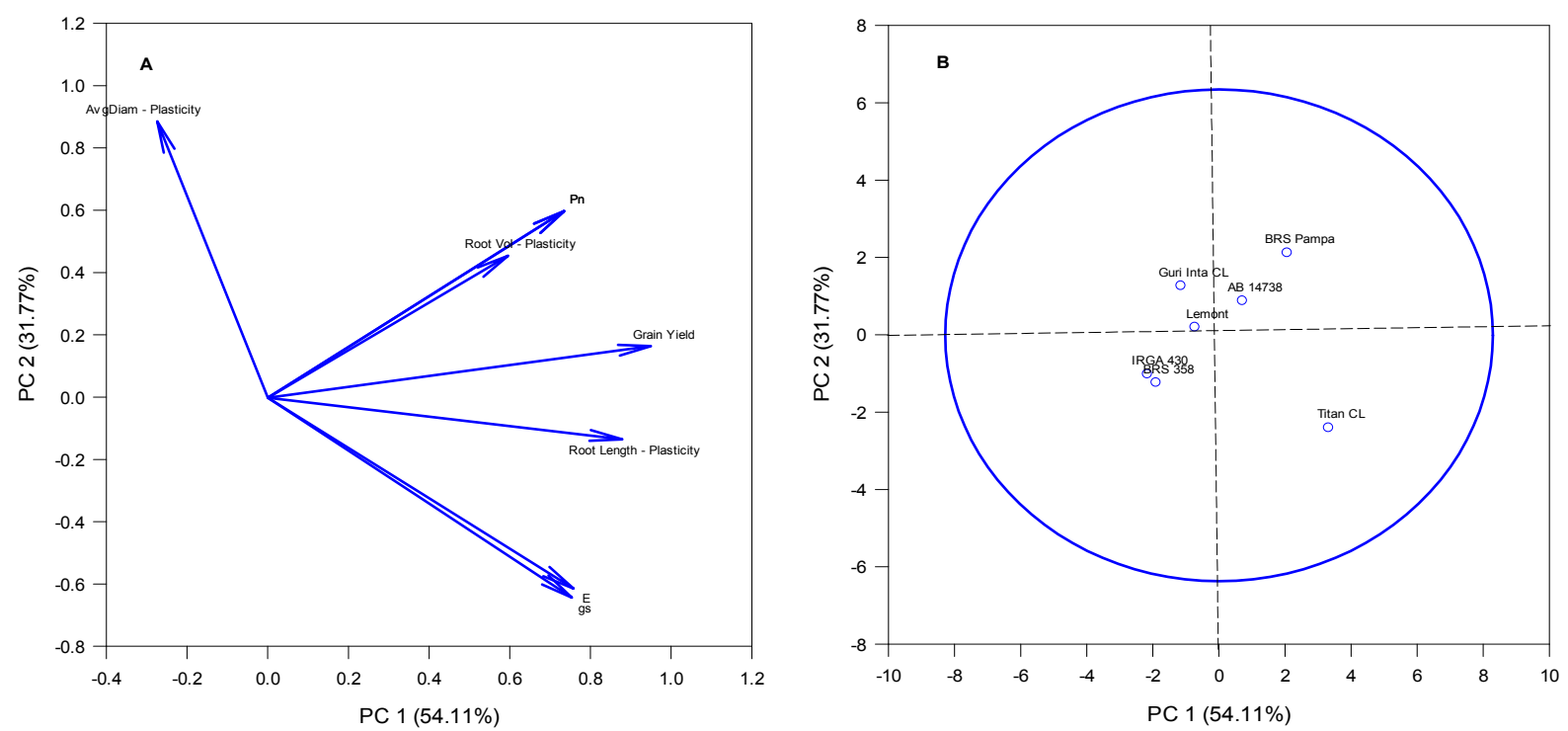

Figure 4. Loading plots (A) and components scores (B) of principal components 1 and 2 of the PCA results, obtained from root plasticity traits, gas exchange and grain yield data from seven genotypes subjected to AWD irrigation management from $\mathrm{R}_{1}$ to $\mathrm{R}_{7}$, under field conditions

Root length plasticity showed a significant correlation with grain yield (average $r=0.72$ ) and also significant negative correlation were found between root AvgDiam plasticity and stomatal conductance, besides of the transpiration rate, at average of $r=0.74$ and 0.70 , respectively. In this way, were recorded a positive significant correlation between Root length plasticity and stomatal conductance, besides transpiration rate, at average of $\mathrm{r}=$ 0.75 and 0.79 , respectively.

\section{Discussion}

According to the historic data recorded in our weather station, between November and February the normal precipitation is about $470 \mathrm{~mm}$ at Low-Land Embrapa Experimental Station (LLEES), as above described. However, during this growth season (November 2017-March 2018), the mean precipitation was $40 \%$ below of average normal rain regime (http://agromet.cpact.embrapa.br/estacao/mensal.html). For this reason, during our study, the AWD management was intensified; thus, the management involving the intervals between the water entry is closed until them to subside until the soil reaches a threshold of water potential $(-40 \mathrm{kPa}$ soil water potential) were four days, approximately. After which, the plots are reflooded and maintained by $48 \mathrm{~h}$ in this conditions, until a new cycle to be restarted.

There were different studies showing that AWD irrigation management can significantly reduces the water used by 30\% (Bouman et al., 2007), until 56\% (Nalley et al., 2015), 23\% (Carrijo et al., 2018), 50\% (Chu et al., 2018) and, in the some cases, were verified increases not only on water use efficiency but also on grain yield. These increases in grain productivity have been common in soil water potential of $15 \mathrm{kPa}$ as a threshold, when the field is reflooded. On the other hand, in our study, even when plants were subjected to this severe soil tension, the mean grain yield decreases were globally small (6\%) across set of evaluated genotypes (Figure 2A). In general, compared to $\mathrm{CF}$ irrigation system, in the AWD were verified small decreases in gas exchange in terms of photosynthesis $(8 \%)$, stomatal conductance $(12 \%)$ and transpiration rate $(9.6 \%)$ (Figures $2 \mathrm{~B}, 2 \mathrm{C}$ and $2 \mathrm{D})$. However, in other way, genotypes showing greater stability across water management were also those that highlighted lower grain yield performance when grown under continuous flooding. 
The plasticity of root system development, especially during some key phases can lead to improve plant performance to various types of water stress. In this sense, is imperative identify and quantify key traits suitable in the design of new plant ideotype to face the increasingly extremes climatic events. For those soil water management where soil surface suffer drought, the plasticity in deep root system development can be considered as an important trait, allowing improve the access of soil moisture at depths. In this way, for severe AWD practice as adopted in this study, the identification of root traits which can improve the plant access to water could lead to the development of a marker to be inserted into breeding procedures aiming the selection of those plants that outperformed for a given trait. By analysis of our data (Figures 2A, 2C, 2D, 3A and 3B), lead us to suggested that a greater TRL plasticity of some genotypes, as highlighted by BRS Pampa and Titan CL hybrids, could potentially contribute to its higher grain yield under AWD management. Additionally, our data indicate that its TRL plasticity is a trait that could contributes to maintain high stomatal conductance leading to sustain high carbon assimilation rate and, consequently, greater grain yield under AWD, as were shown by these two genotypes. Importantly emphasize that BRS Pampa cultivar has significantly greater TRL and TRV plasticity, greater photosynthesis performance and highest grain yield under AWD, besides its greater yield stability across adopted water management. In this way, according some studies, small roots diameter with greater seminal root length enable plants to efficiently increase hydraulic conductance via increasing surface area in contact with soil water, which can allowing increase the volume of soil that can be explored for water, and, also, improve root hydraulic conductivity by decreasing the appoplastic barrier of water entering the xylem (Comas et al., 2012; Hernández et al., 2010). Additionally, decrease in root diameter has been associated to improvement in plant water acquisition when grown under water deficit conditions (Wasson et al., 2012). Our data show a negative and significant correlation between total root diameter (TRD) and stomatal conductance (average $\mathrm{r}=0.74$ ). Accordingly to Comas and co-workers (Comas et al., 2013) will be need advances in the understanding of root functional traits and how these traits are related to whole plant strategies whether our aim is to increase crop yield under different water deficit conditions. These authors highlight that some traits as such small fine root diameters, long specific root length and a considerable root length density, especially at depths in soil with available water, as greater contributors to maintain higher crop productivity under different water availability conditions. Additionally, in our study were also highlighted the correlation between photosynthesis rate and grain yield (average $r=0.85$ ) in those treatments subjected to AWD water management. In this sense, different studies has demonstrated the contribution of plasticity in root length density or total root length (Sandhu et al., 2016; Tran et al., 2015) and the role of lateral root length in the increase of shoot biomass, water uptake and photosynthesis when plants are grown under some water deficit degree (Kano-Nakata et al., 2013).

We emphasize that, in general, were highlighted increases in total root length (32\%) and total root volume (48\%) for set of genotypes subjected to AWD management. Under AWD, Titan CL hybrid and BRS Pampa cultivar increased the total root volume in $267 \%$ and $740 \%$, respectively; for total root length, the increases were $529 \%$ and $455 \%$, respectively. BRS Pampa increased in $27 \%$ its root average diameter and Titan CL hybrid showed a decrease of $24 \%$ for this same parameter when managed under AWD. At same time, these two genotypes showed higher grain yield across set of evaluated genotypes. The root plasticity shown by these two genotypes allowed them to explore efficiently water and nutrients by its deepening in the soil profile (from zero to $20 \mathrm{~cm}$ depth, when a hardpan is found in our experimental station) whether compared to those without this plasticity capacity; which in turn, allowed them to maintain greater cell turgor and consequently, reduce its metabolic energetic costs involved in this pathways defense (e.g., osmotic adjustment and antioxidative mechanisms) (Lisei-de-Sá et al., 2017; Weber et al., 2014).

As highlighted by some authors, in general the tropical japonica rice have fewer tillers capacity but deeper root systems whether compared to other rice ecotypes (e.g., indica, aus, rayada) (Lafitte et al., 2006). Additionally, has been highlighted that the root cone angle is an important trait in rice whether consider it large role in the soil volume that is exploited (Bettembourg et al., 2017); these author show that the indica accessions recorded lower angle values (range from 21.8 to $93.0^{\circ}$ ) whereas japonica accessions (range 36.3 to $164.4^{\circ}$ ) show more ample angle values. Although is a consensus about the potential of the root traits to enhance or at least contribute with higher grain yield stability under alternate AWD irrigation, is imperative to increase the basic knowledge about root traits and especially it functioning when plants are subjected to AWD water management or even to drought conditions. Thus, progresses in the understanding of regulatory pathways and underlying the molecular components that regulate root growth, and consequently the root system architecture will serves as a starting point to guide the future breeding efforts aiming to obtain plant ideotypes suitable for approaches that aiming rationalize the water use across of the different strategies actually available. 
Although phenotypic plasticity is heritable (Nicotra \& Davidson, 2010), its exploration is not usually a target in the breeding program for AWD management or even for hard water deficit conditions. As described above, the effort made by Brazilian rice breeding along of decades were concentrated in the development of cultivars adapted to continuous flooding irrigation system. However, take into account the prediction of negative impacts of climate change on the rain distribution for this region in the future, besides of the increases in the energetic costs for water capture and its distribution by farmers, will determine that the breeding program change its efforts aiming to construct new plant ideotype (root ideotype and allometry), which can optimize and supporting innovations in water management practice in the rice paddy for south Brazilian region.

These results may provide useful information for breeding efforts, allowing glimpse a potential to explore the germplasm bank aiming to construct plant ideotypes with high and stable yield under AWD irrigation management, without penalties when grown under CF conditions. Thus, efforts of breeding should be concentrated to provide future cultivars with such traits to promote the optimization, stimulate the adoption and dissemination of water saving use as such AWD practice. In this context, is imperative highlight that is a first physiological effort made by Brazilian rice breeding, which integrate physiological approaches into the rice breeding program aiming to uncover rice root traits which can contribute do water and energy saving. The advances obtained in this study will define the strategies for new experiments aiming elucidate the mechanisms triggered and its phenotypic plasticity traits expressed in response to AWD practice; this knowledge will be a starting point to define the new plant ideotypes for the future climate scenarios. These progress will allow optimize and implementing this water-saving management technologies, leading to a more sustainable rice system production for Brazilian southern region.

\section{Conclusions}

The adoption of severe AWD irrigation management trigger the root plasticity (e.g., total root volume and total root length) in rice genotype-dependent response manner. BRS Pampa cultivar and Titan CL hybrid showed the greater plasticity index for total root length and total root volume. Our data suggests that under severe AWD management, root plasticity in terms of more total root length and total root volume at $0-20 \mathrm{~cm}$ depth can leads to some contribution degree for higher grain yield and for its stability under AWD practice. These results can serves as a starting point to additional efforts via physiological breeding approaches aiming the construction of rice plant ideotypes more suitable for AWD management, especially take into account its contributions to mitigate potential impacts of future climate changes on food production.

\section{References}

Bettembourg, M., Dardou, A., Audebert, A., Thomas, E., Frouin, J., Guiderdoni, E., ... Courtois, B. (2017). Genome-wide association mapping for root cone angle in rice. Rice, 10, 45. https://doi.org/10.1186/ s12284-017-0184-z

Bouman, B. A. M., Lampayan, R. M., \& Tuong, T. P. (2007). Water managment in rice: Coping with water scarcity. IRRI, Philippines.

Brito, G. G., Caixeta, E. T., Gallina, A. P., Zambolim, E. M., Zambolim, L., Diola, V., \& Loureiro, M. E. (2010). Inheritance of coffee leaf rust resistance and identification of aflp markers linked to the resistance gene. Euphytica, 173(2), 255-264. https://doi.org/10.1007/s10681-010-0119-x

Brito, G. G., Fagundes, P. R. R., Teló, G. M., Abreu, A. G., Júnior, A. M. M., Franco, D. F.,... Petrine, J. A. (2016) Impact of supra-optimal temperatures on physiology and yield in rice field. Journal of Agricultural Science, 8(2).

Brito, G. G., Sofiatti, V., Lima, M. M. A., Carvalho, L. P., \& Silva-Filho, J. L. (2011). Physiological traits for drought phenotyping in cotton. Acta Scientiarum Agronomy, 33(01), 117-125. https://doi.org/10.4025/ actasciagron.v33i1.9839

Bronselaer, B., Winton, M., Griffies, S. M., Hurlin, W. J., Rodgers, K. B., Sergienko, O. V., ...Russell, J. L. (2018). Change in future climate due to antarctic meltwater. Nature. https://doi.org/10.1038/s41586-018 $-0712-\mathrm{z}$

Carrijo, D. R., Akbar, N., Reis, A. F. B., Li, C., Gaudin, A. C. M., Parikh, S. J., ... Linquist, B. A. (2018). Impacts of variable soil drying in alternate wetting and drying rice systems on yields, grain arsenic concentration and soil moisture dynamics. Field Crops Research, 222, 101-110. https://doi.org/ 10.1016/j.fcr.2018.02.026 
Carrijo, D. R., Lundy, M. E., \& Linquist, B. A. (2017). Rice yields and water use under alternate wetting and drying irrigation: A meta-analysis. Field Crops Research, 203, 173-180. https://doi.org/10.1016/ j.fcr.2016.12.002

Chu, G., Chen, T., Chen, S., Xu, C., Wang, D., \& Zhang, X. (2018). Agronomic performance of drought-resistance rice cultivars grown under alternate wetting and drying irrigation management in southeast china. The Crop Journal. https://doi.org/10.1016/j.cj.2018.04.005

Comas, L. H., Becker, S. R., Cruz, V. M., Byrne, P. F., \& Dierig, D. A. (2013). Root traits contributing to plant productivity under drought. Front Plant Sci., 4, 442. https://doi.org/10.3389/fpls.2013.00442

Comas, L. H., Mueller, K. E., Taylor, L. L., Midford, P. E., Callahan, H. S., \& Beerling, D. J. (2012). Evolutionary patterns and biogeochemical significance of angiosperm root traits. International Journal of Plant Sciences, 173(6), 584-595. https://doi.org/10.1086/665823

CONAB. (2018). Série histórica das safras. Retrieved from https://www.conab.gov.br/info-agro/safras/ serie-historica-das-safras

Counce, P., Keisling, T. C., \& Mitchell, A. J. (2000). A uniform, objective, and adaptive system for expressing rice development. Crop Science, 40(2), 436-443. https://doi.org/10.2135/cropsci2000.402436x

Diola, V., Brito, G. G., Caixeta, E. T., Pereira, L. F. P., \& Loureiro, M. E. (2013). A new set of differentially expressed signaling genes is early expressed in coffee leaf rust race ii incompatible interaction. Functional \& Integrative Genomics, 13(3), 379-389. https://doi.org/10.1007/s10142-013-0330-7

Diola, V., de Brito, G. G., Caixeta, E. T., Maciel-Zambolim, E., Sakiyama, N. S., \& Loureiro, M. E. (2011). High-density genetic mapping for coffee leaf rust resistance. Tree Genetics \& Genomes, 7(6), 1199-1208. https://doi.org/10.1007/s11295-011-0406-2

Fageria, N. K., Wander, A. E., \& Silva, S. C. (2014). Rice (Oryza sativa) cultivation in brazil. Indian Journal of Agronomy, 59(3), 350-358.

Fan, S., \& Brzeska, J. (2014). Feeding more people on an increasingly fragile planet: China's food and nutrition security in a national and global context. Journal of Integrative Agriculture, 13(6), 1193-1205. https://doi.org/10.1016/S2095-3119(14)60753-X

Guimarães, C. M., Stone, L. F., Brito, G. G. D., \& Heuert, J. (2017). Evaluation of water-stress tolerance of acala sj 2 and auburn 2 cotton cultivars in a phenotyping platform. Revista Ambiente \& Água, 12, 629-642. https://doi.org/10.4136/ambi-agua.2105

Henry, A., Gowda, V. R. P., Torres, R. O., McNally, K. L., \& Serraj, R. (2011). Variation in root system architecture and drought response in rice (Oryza sativa): Phenotyping of the oryzasnp panel in rainfed lowland fields. Field Crops Research, 120(2), 205-214. https://doi.org/10.1016/j.fcr.2010.10.003

Hernández, E. I., Vilagrosa, A., Pausas, J. G., \& Bellot, J. (2010). Morphological traits and water use strategies in seedlings of mediterranean coexisting species. Plant Ecology, 207(2), 233-244. https://doi.org/ $10.1007 / \mathrm{s} 11258-009-9668-2$

Jacquemin, J., Bhatia, D., Singh, K., \& Wing, R. A. (2013). The international oryza map alignment project: Development of a genus-wide comparative genomics platform to help solve the 9 billion-people question. Curr Opin Plant Biol, 16(2), 147-56. https://doi.org/10.1016/j.pbi.2013.02.014

Kaiser, H. F. (1958). The varimax criterion for analytic rotation in factor analysis. Psychometrika, 23(3), 187-200. https://doi.org/10.1007/BF02289233

Kano-Nakata, M., Gowda, V. R. P., Henry, A., Serraj, R., Inukai, Y., Fujita, D., ... Yamauchi, A. (2013). Functional roles of the plasticity of root system development in biomass production and water uptake under rainfed lowland conditions. Field Crops Research, 144, 288-296. https://doi.org/10.1016/j.fcr.2013.01.024

Lafitte, R., Bennett, J., \& Kathiresan, A. (2006). Drought adaptation in rice. In J. M. Ribaut (Ed.), Drought adaptation in cereals (pp. 301-334). Seaworthy Press, Inc, New York.

Lisei-de-Sá, M. E., Arraes, F. B. M., Brito, G. G., Beneventi, M. A., Lourenço-Tessutti, I. T., Basso, A. M. M., ... Grossi-de-Sa, M. F. (2017). Atdreb2a-ca influences root architecture and increases drought tolerance in transgenic cotton . Agricultural Sciences, 8(10),1195-1225. https://doi.org/10.4236/as.2017.810087 
Moura, D. S., Brito, G. G., Campos, A. D., Moraes, I. L., Porto, G. S. F., Teixeira, S. B., ... Deuner, S. (2017). Non-structural carbohydrates accumulation in contrasting rice genotypes subjected to high night temperatures. Journal of Agricultural Science, 9(12), 302-315. https://doi.org/10.5539/jas.v9n12p302

Moura D. S., Brito G. G., Fagundes P. R., \& Castro A. (2018a). Cold tolerance in rice plants: Phenotyping procedures for physiological breeding. Journal of Agricultural Science, 10(1), 313-324.

Moura, D. S., Moraes, I. L., Armensto, R. S., Silva, R. S., Reolon, F., Borela, J., ... Deuner, S. (2018b). Above-optimum temperature-induced differential photosynthetic and roots morphometric responses in two contrasting rice genotypes. Journal of Agricultural Science and Technology, 7, 309-319.

Nalley, L., Linquist, B., Kovacs, K., \& Anders, M. (2015). The economic viability of alternative wetting and drying irrigation in arkansas rice production. Agronomy Journal, 107(2), 579-587. https://doi.org/ 10.2134/agronj14.0468

Nicotra, A. B., \& Davidson, A. (2010). Adaptive phenotypic plasticity and plant water use. Functional Plant Biology, 37, 117-137. https://doi.org/10.1071/FP09139

Niones, J. M., Suralta, R. R., Inukai, Y., \& Yamauchi, A. (2012). Field evaluation on functional roles of root plastic responses on dry matter production and grain yield of rice under cycles of transient soil moisture stresses using chromosome segment substitution lines. Plant and Soil, 359(1), 107-120. https://doi.org/ 10.1007/s11104-012-1178-7

Olivier, J. G. J., Schure, K. M., \& Peters, J. A. H. W. (2017). Trends in global $\mathrm{CO}_{2}$ and total greenhouse gas emissions. PABLO Publishers vol 2983. Netherlands Environmental Assessment Agency, Netherlands.

O’Toole, J. C., \& Bland, W. L. (1987). Genotypic variation in crop plant root systems. In N. C. Brady (Ed.), Advances in agronomy (vol 41, pp. 91-145). Academic Press. https://doi.org/10.1016/S0065-2113(08) 60803-2

Parfitt, J. M. B., da Silva, J. T., Bueno, M. V., Timm, P. de A., de Campos, A. D. S., Aires, T. do A., \& Timm, L. C. (2018). Quantificação da Demanda Hídrica na Cultura do Arroz em Função do Manejo da Irrigação por Inundação. Boletim de Pesquisa e Desenvolvimento 313. Embrapa Clima Temperado, Pelotas, RS.

Sandhu, N., Raman, K. A., Torres, R. O., Audebert, A., Dardou, A., Kumar, A., \& Henry, A. (2016). Rice root architectural plasticity traits and genetic regions for adaptability to variable cultivation and stress conditions. Plant Physiology, 171(4), 2562-2576. https://doi.org/10.1104/pp.16.00705

SigmaPlot 13.0. Systat Software San Jose C. Sigmaplot—Exact graphs and data analysis.

SOSBAI. (2016). Recomendações técnicas da pesquisa para o sul do Brasil (Vol. 31). Reunião técnica da cultura do arroz irrigado. SOSBAI, Pelotas.

Suralta, R. R., Inukai, Y., \& Yamauchi, A. (2010). Dry matter production in relation to root plastic development, oxygen transport, and water uptake of rice under transient soil moisture stresses. Plant and Soil, 332(1), 87-104. https://doi.org/10.1007/s11104-009-0275-8

Tran, T. T., Kano-Nakata, M., Suralta, R. R., Menge, D., Mitsuya, S., Inukai, Y., \& Yamauchi A. (2015). Root plasticity and its functional roles were triggered by water deficit but not by the resulting changes in the forms of soil $\mathrm{n}$ in rice. Plant and Soil, 386(1), 65-76. https://doi.org/10.1007/s11104-014-2240-4

Uga, Y., Sugimoto, K., Ogawa, S., Rane, J., Ishitani, M., Hara, N., ... Yano, M. (2013). Control of root system architecture by deeper rooting 1 increases rice yield under drought conditions. Nat Genet, 45(9), 1097-102. https://doi.org/10.1038/ng.2725

Wasson, A. P., Richards, R. A., Chatrath, R., Misra, S. C., Prasad, S. V., Rebetzke, G. J., .. Watt, M. (2012). Traits and selection strategies to improve root systems and water uptake in water-limited wheat crops. $J$ Exp Bot, 63(9), 3485-98. https://doi.org/10.1093/jxb/ers111

Weber, R. L., Wiebke-Strohm, B., Bredemeier, C., Margis-Pinheiro, M., de Brito, G. G., Rechenmacher, C., ... Bodanese-Zanettini, M. H. (2014). Expression of an osmotin-like protein from solanum nigrum confers drought tolerance in transgenic soybean. BMC Plant Biol, 14, 343. https://doi.org/10.1186/s12870 $-014-0343-y$

Yang, J. M., Zhou, Q., \& Zhang, J. (2017). Moderate wetting and drying increases rice yield and reduces water use, grain arsenic level, and methane emission. The Crop Journal, 5, 151-158. https://doi.org/10.1016/ j.cj.2016.06.002 
York, L. M., Nord, E. A., \& Lynch, J. P. (2013). Integration of root phenes for soil resource acquisition. Frontiers in Plant Science, 12, 1-15. https://doi.org/10.3389/fpls.2013.00355

\section{Copyrights}

Copyright for this article is retained by the author(s), with first publication rights granted to the journal.

This is an open-access article distributed under the terms and conditions of the Creative Commons Attribution license (http://creativecommons.org/licenses/by/4.0/). 